\title{
Global and cross-country analysis of exposure of vulnerable populations to heatwaves from 1980 to 2018
}

\author{
Jonathan Chambers ${ }^{1}$
}

Received: 11 September 2019 / Accepted: 29 September 2020 /Published online: 9 October 2020

(C) The Author(s) 2020

\begin{abstract}
Heatwaves have become more frequent and intense due to anthropogenic global warming and have serious and potentially life-threatening impacts on human health, particularly for people over 65 years old. While a range of studies examine heatwave exposures, few cover the whole globe and very few cover key areas in Africa, South America, and East Asia. By using global gridded climate reanalysis, population, and demographic data, this work analyses trends in change in exposure of vulnerable populations to heatwaves, providing global and per-country aggregate statistics. The difference between the global mean of heatwave indexes and the mean weighted by vulnerable population found that these populations are experiencing up to five times the number of heatwave days relative to the global average. The total exposures, measured in person-days of heatwave, highlight the combined effect of increased heatwaves and aging populations. In China and India, heatwave exposure increased by an average of 508 million person-days per year in the last decade. Mapping of changes per country highlighted significant exposure increases, particularly in the Middle East and in South East Asia. Major disparities were found between the heatwave exposures, country income group, and country health system capacity, thus highlighting the significant inequalities in global warming impacts and response capacities with respect to health across countries. It is therefore of prime importance that health development and response are coordinated with climate change mitigation and adaptation work.
\end{abstract}

Keywords Global warming $\cdot$ Health $\cdot$ Heatwaves $\cdot$ Indicators

Electronic supplementary material The online version of this article (https://doi.org/10.1007/s10584-02002884-2) contains supplementary material, which is available to authorized users.

Jonathan Chambers

jonathan.chambers@unige.ch

1 Chair for Energy Efficiency, Institute for Environmental Sciences and Forel Institute, University of Geneva, Boulevard Carl-Vogt 66, 1205 Geneva, Switzerland 


\section{Introduction}

Anthropogenic global warming is driving an observed increase in the frequency, intensity, and duration of global heatwaves and warm spells, with these trends projected to continue in the future (IPCC 2013a; Perkins-Kirkpatrick and Gibson 2017; Perkins et al. 2012). The World Health Organization (WHO) has identified climate change as a global risk factor for health (WHO 2009), with heatwaves presenting a particularly acute risk. Furthermore, vulnerability to heatwaves is not uniform - certain age groups are more susceptible to ill effects, while other factors including prevalence of certain diseases, condition of infrastructure, and health system status all contribute to the overall risk factor (Watts et al. 2019, 2018, 2017, 2016).

\subsection{Health impacts of heatwaves}

Heatwaves have been shown to have serious and potentially life-threatening impacts on human health (Anderson and Bell 2009; Basu and Samet 2002; Campbell et al. 2018; Hajat and Kosatky 2010; Krau 2013), with specific events noted as public health disasters such as in Chicago during July 1995 and in France during August 2003 (Krau 2013). High temperatures can cause heat stroke, heat exhaustion, heat syncope, and heat cramps, with heat stroke being particularly associated with sedentary elderly people (Kilbourne 1997). It has been observed that health effects increase as temperatures rise above certain heatwave thresholds (Lin et al. 2009). Although there is evidence of acclimatisation to local hot climates, all persons are negatively affected by temperatures in the extreme percentiles of their local climatologies (Anderson and Bell 2009), with statistically significant effects on mortality when temperatures surpass the 99th percentile even in locations which display evidence of adaptation to heatwaves (Gasparrini et al. 2015a). It has been noted that high night-time (minimum) temperatures in particular have high health impacts because of a lack of night-time relief from excessive heat, which would allow the human body to rest and recover from heat stress (Smith and Levermore 2008; Watts et al. 2015).

The health risks associated with heatwaves have been shown to be higher for certain groups of people. Increased risk has been associated with those living in urban areas (with high population density), possible due to urban heat island effects (Basu and Samet 2002; Watts et al. 2018). Persons with pre-existing cardiovascular and chronic respiratory conditions, as well as those with diabetes, have been found to have higher mortality due to heatwaves (mainly due to stress on the cardiovascular and respiratory systems) (Basu and Samet 2002; Gasparrini et al. 2015b; Kenney and Hodgson 1987). Older persons, generally identified in studies as those over 65 years old, are also at increased risk (Anand and Bärnighausen 2007; Campbell et al. 2018; Guo et al. 2017; Li et al. 2015; Oudin Åström et al. 2011). Causes for this include their lower ability to thermoregulate body temperatures (Basu and Samet 2002; Kenney and Hodgson 1987), the prevalence of the aforementioned pre-existing medical conditions within this age group, and possibly increased social isolation which has been identified as a risk factor (Buscail et al. 2012).

Studies have considered the health impacts of past heatwaves by comparing health outcomes from heatwave events with local or global heatwave indexes. In general, this has been performed for a selection of cities or regions (Anderson and Bell 2009; Campbell et al. 2018; Li et al. 2015; Russo et al. 2015; Scalley et al. 2015; Zhao et al. 2019, 2018) or by collecting many individual studies (Mora et al. 2017). Guo et al. (2018, 2017) combined mortality and climate data to estimate heatwave impacts for 412 communities in 20 regions. 
However, while there has been extensive research on heatwaves and health in Europe, North America, and Australia, significant geographical areas have limited coverage. For example, in reviews of case studies, by Campbell et al. (2018) and Mora et al. (2017), four studies were found for Africa and seven for South America. More recent works include studies for South Africa (Wright et al. 2019) Senegal (Sarr et al. 2019), and Brazil (Zhao et al. 2018). The dataset developed by Guo et al. (2018) included no data for Africa and limited data for Brazil, Chile, and Columbia. In these regions, data challenges currently make it difficult to estimate deaths attributable to heatwaves (Wright et al. 2019). Gaps in coverage mean that atrisk areas may not be identified and make it difficult to compare trends globally. Using a casestudy based methodology limits the geographic coverage.

Campbell et al. (2018) highlighted that areas with the least coverage also have lower wealth per adult, while Herold et al. (2017) found that temperature extremes increased more in lowversus high-income countries. Numerous studies show evidence that countries with lower levels of wealth tend to have reduced numbers of health workers, which leads to worse health outcomes (Anand and Bärnighausen 2007; Speybroeck et al. 2006). WHO regions with poor coverage of heatwave impact studies also have lower numbers of health workers per population, notably the Africa region with an average of 2.5 medical doctors per 10,000 people (compared with 34 per 10,000 for the Europe region). Indeed, Guo et al. (2016) found a decrease in heatwave-related mortality over the period 1993-2006 in Australia, Canada, Japan, South Korea, Spain, the UK, and the USA, which all have high numbers of health workers and therefore the capacity to develop improved heatwave response measures. This highlights the need for research covering underserved regions.

\subsection{Heatwave indicators}

No single internationally accepted definition of heatwave index exists. The World Meteorological Organization (WMO), following a survey of country practices, suggests heatwaves be defined as "A marked unusual hot weather (Max, Min and daily average) over a region persisting at least two consecutive days during the hot period of the year based on local climatological conditions, with thermal conditions recorded above given thresholds" (WMO 2015).

Existing heatwave indexes follow the WMO guideline but differ significantly in the details, such as the thresholds (number of days required, threshold values or percentiles, normalisation approach). A range of climate extreme indicators have been proposed by the Expert Team on Climate Change Detection and Indices, notably the warm spell duration indicator (WSDI) defined as count of days part of a 6-day window when maximum temperature is above the 90th percentile. Maximum temperature has been used to define heatwave conditions as it approximates the maximum thermal stress on the body (Basagaña et al. 2011; Campbell et al. 2018; Kilbourne 1997; Perkins 2015). However, a study of mortality during the 2003 Paris heatwave found that high minimum temperature had more impact on increased probability of death in people over 65 than mean or maximum temperatures (Laaidi et al. 2012; Xu et al. 2018), highlighting the importance of night-time respite for the body to recover during heatwave periods (Basu and Samet 2002).

In the author's previous work by Watts et al. (2017, 2018, 2019), a heatwave was defined as a period of four or more days at a given location where the minimum daily temperature was greater than the 99th percentile of the distribution of minimum daily temperature at that location over the 1986-2005 reference period for the summer months (June, July, August in 
the northern hemisphere, December, January, February in the southern hemisphere). However, this definition may fail to suitably reflect conditions in countries or regions where the hottest months do not coincide with the summer period defined above, for example northern India typically experiences its yearly maximum temperatures in May.

There are several aspects of heatwaves to be measured such as frequency, length, and magnitude, and there are any number of formulations of indexes to measure these (Perkins 2015). With respect to health, there is a need to determine from what duration of heatwave the effects start to be felt. Epidemiological evidence found that a run of at least three consecutive days of high temperatures was associated with increased mortality (Basu and Samet 2002; Nairn and Fawcett 2013). Furthermore, heatwave indexes based on local temperature percentiles, rather than absolute thresholds, are more relevant because they can be applied globally and also help reflect a degree of local acclimatisation to regional conditions (Nairn and Fawcett 2013; Perkins 2015). These factors have notably been considered in the Australian Bureau of Meteorology's heatwave indicators for Australia (Nairn and Fawcett 2013).

\subsection{Research aims}

Previous studies were not able to assess heatwave impacts in all locations, which is mainly due to the use of case-study based methods which limit their geographic scope. They are therefore limited in giving a global overview, particularly for lower-income countries which have been shown to be more exposed to increasing temperature extremes.

This study aims at providing a global and cross-country analysis of exposure of vulnerable persons to heatwaves. We build on our previous work in the Lancet Climate Countdown, which developed indicators of heatwave health risk through the exposure of persons over 65 to change in heatwaves based on global climate and demographic datasets (Watts et al. 2015, 2016, 2017, 2018). This study aims at further exploring the factors of vulnerability and variation of vulnerability across countries by combining heatwave exposure with country wealth and health system metrics. Global and per-country values are presented to assess the variability in heatwave exposure across different regions.

\section{Methods}

This section presents the definitions of the heatwave indices used for the study and the method of calculating the change and trends. The method combines heatwave indexes with global population, demographic, and health data covering the period from 1980 to 2018. This enables a global and cross-country analysis of heatwave exposure trends among vulnerable people. Table 1 summarises the datasets used; further details are given in the following section. The method was implemented in Python using the Xarray package (Hoyer and Hamman 2016). Note: a grid cell in the rectangular gridded data is denoted by its coordinates $(i, j)$.

\subsection{Datasets}

\subsubsection{Climate data}

This work used climate reanalysis data from the ERA- 5 project at $0.5^{\circ}$ grid resolution for the years 1980-2018. Temperature at $2 \mathrm{~m}$ from the earth's surface was acquired at hourly time resolution, 
Table 1 Summary of datasets used

\begin{tabular}{|c|c|c|c|c|c|}
\hline Data source & Description & $\begin{array}{l}\text { Spatial } \\
\text { resolution }\end{array}$ & Time coverage & $\begin{array}{l}\text { Time } \\
\text { resolution }\end{array}$ & Variables \\
\hline ERA-5 & $\begin{array}{l}\text { Global weather } \\
\text { reanalysis data }\end{array}$ & $0.5^{\circ}$ grid & 1980-2018 & Hourly & Temperature at surface \\
\hline NASA GPWv4 & Global population data & $0.5^{\circ}$ grid & $\begin{array}{r}\text { 2000-2018; } 2010 \\
\text { (demographics) }\end{array}$ & Yearly & $\begin{array}{l}\text { Population total and by } \\
\text { age band }\end{array}$ \\
\hline ISIMIP & Global population data & $0.5^{\circ}$ grid & $1950-2010$ & Yearly & Population total \\
\hline UN WPP & Demographic data & Country & $1950-2018$ & Yearly & $\begin{array}{l}\text { Population by age } \\
\text { band }\end{array}$ \\
\hline WHO & Health metrics & Country & Various & Yearly & $\begin{array}{l}\text { Doctors per } 10,000 \\
\text { persons }\end{array}$ \\
\hline World Bank & Socioeconomic metrics & Country & Various & Yearly & Income group \\
\hline
\end{tabular}

and daily summaries of mean, min, and max temperature were generated from the hourly data. Percentiles of mean, min, and max temperature were computed for the period 1986-2005. The daily values and percentiles are available as open access datasets ${ }^{1}$ (Chambers 2019a, b).

\subsubsection{Population}

Gridded population and demographic data at $0.5^{\circ}$ grid resolution were obtained from the NASA Socioeconomic Data and Applications Center (SEDAC) Global Population of the World version 4 (GPWv4) (NASA SEDAC and CIESIN 2016) for the years 2000-2018. For the years $1980-2000$, historical $0.5^{\circ}$ resolution population data from the Inter-Sectoral Impact Model Intercomparison Project (ISIMIP) were used (Goldewijk et al. 2017). These datasets were readily combined as they share a common coordinate system and it was found that population totals were continuous across them.

\subsubsection{Demographics}

NASA SEDAC GPWv4 provided gridded demographic data for 2010 as a set of grids of total population per 5-year age band. The UN World Population Program (WPP) provides countrylevel demographic statistics for 1950 onwards (extended through modelling until 2100), and the values for the median scenario were retained (UN 2019). The gridded demographic data was adjusted for each year from 1980 to 2018 such that the mean demographic distribution for the grid cells corresponding to each country matched the country-level values. This allowed to maintain the high spatial resolution data from 2010 for all years studied, under the simplifying assumption that the relative spatial distribution of population for each age band within each country remained approximately constant. This was achieved as follows:

- The GPWv4 gridded demographic age band totals per grid cell for 2010 were converted to fractions such that the sum over age bands per grid cell equals 1.

- The WPP demographic age band totals per country per year were converted into fractions per age band per year, such that the sum over age bands per country per year equals 1 .

- For each country, the appropriate section of gridded data was selected using the gridded country codes provided by the GPWv4 dataset.

\footnotetext{
$\overline{{ }^{1} \text { https://zenodo.org/record/3403951 }}$; https://zenodo.org/record/3403963
} 
- For each year, for each 5-year age band, the ratio $\delta_{\text {age }}^{y}$ of the fraction per age band for that year to the fraction per age band for 2010 was calculated (Eq. 1).

$$
\delta_{y}^{\text {age }}=f_{y}^{\text {age }} / f_{2010}^{a g e}
$$

- To obtain the adjusted grid cell value, the value for 2010 was multiplied by $\delta_{\text {age }}^{y}$ for each year for each grid cell (Eq. 2).

$$
f_{y, i, j}^{\mathrm{age}}=\delta_{y}^{\mathrm{age}} f_{2010, i, j}^{\mathrm{age}}
$$

- The output grids of fraction of population per age band for each year were assembled by merging the individual grids for each country.

For each year, the total population over 65 per grid cell $P_{y, i, j}^{65+}$ was calculated using Eq. 3:

$$
P_{y, i, j}^{65+}=f_{y, i, j}^{65+} \times P_{y, i, j}^{\mathrm{total}}
$$

\subsubsection{Health and economic data}

Country-level health metrics were obtained from the WHO Global Health Observatory data repository ("WHO Global Health Observatory," 2019) and associated with other country data. World Bank Income groups (low income, lower-middle income, upper-middle income, high income) were associated with each country (World Bank 2018).

\subsection{Definition of heatwave indexes}

In this work, a heatwave was defined as a period of 4 or more days at a given location where the minimum daily temperature was greater than the 99th percentile of the distribution of minimum daily temperatures at that location for all months of the year over the 1986-2005 baseline period (thereby relaxing the restriction to summer months used in (Watts et al. 2019, $2018,2017))$. The baseline period was chosen in accordance with the practice of the Intergovernmental Panel on Climate Change (IPCC 2013b).

Five descriptive indexes were calculated based on the heatwave definition to evaluate trends in heatwave frequency and intensity in terms of duration and temperature anomaly (Table 2).

\subsubsection{Heatwave count, days, and degree days}

To calculate the heatwave count, heatwave days, and heatwave degree days metrics for a given year, we extract for each grid cell the sequences of days which correspond to the heatwave definition above. For each day $d$ and grid cell $(i, j)$, the threshold exceedance $E_{d, i, j}$ is calculated according to Eq. 4:

$$
E_{d, i, j}=\left\{\begin{array}{c}
1 \text { if } \operatorname{Tmin}_{d, i, j}>T 99_{i, j} \\
0 \text { otherwise }
\end{array}\right.
$$


Table 2 Summary of descriptive indexes

\begin{tabular}{|c|c|c|}
\hline Heatwave index & Description & Units \\
\hline Heatwave count & Count of distinct heatwaves during a year per grid cell & Number \\
\hline Heatwave days & $\begin{array}{l}\text { Number of days of heatwave per year per grid cell, which measures the } \\
\text { trends in total duration of heatwaves }\end{array}$ & Days \\
\hline Heatwave degree days & $\begin{array}{l}\text { Sum of degree days of heatwave per year per grid cell, which captures } \\
\text { both the change in duration and change in intensity of heatwaves }\end{array}$ & ${ }^{\circ} \mathrm{C}$ days \\
\hline Heatwave mean length & $\begin{array}{l}\text { Mean length in days of individual heatwave per year per grid cell. } \\
\text { Measures the trends in duration per heatwave }\end{array}$ & Days \\
\hline $\begin{array}{l}\text { Heatwave mean degrees } \\
\text { over threshold }\end{array}$ & $\begin{array}{l}\text { Mean }{ }^{\circ} \mathrm{C} \text { above the heatwave threshold per year per grid cell, measuring } \\
\text { the trends in heatwave intensity }\end{array}$ & ${ }^{\circ} \mathrm{C}$ \\
\hline
\end{tabular}

where $T \min _{d, i, j}$ is the daily minimum temperature and $T 99_{i, j}$ is the 99th percentile of daily minimum temperatures. The degree difference $D D_{d, i, j}$ is calculated for each day between $T \min _{d, i, j}$ and $T 99_{i, j}$, where the difference is positive (Eq. 5):

$$
D D_{d, i, j}=\max \left(T \min _{d, i, j}-T 99_{i, j}, 0\right)
$$

This produces two time series vectors per grid cell, $E_{i, j}$ and $D D_{i, j}$. These are split into sets of continuous sequences of days where $E_{d, i, j}=1$ and the length of each sequence is $\geq 4$, i.e., where heatwave conditions occur for 4 or more consecutive days. The sequence information from $E_{i, j}$ is used to split the degree difference vector $D D_{i, j}$ (see supplementary information for further details). From these sets of sequences, we calculate for each year $y$ :

- Heatwave Count $t_{y, i}$ equals the count of the number of distinct sequences of days for a grid cell for a year.

- Heatwave Days $y_{y, i, j}$ equals the sum of lengths of the sequences for a grid cell for a year.

- Heatwave Degree Days $y_{y, i, j}$ equals the sum of all degree difference sequences for a grid cell for a year.

\subsubsection{Heatwave mean length}

The heatwave mean length is the mean number of days per heatwave for a given year, calculated as the number of heatwave days divided by the number of individual heatwaves for a grid cell $(i, j)$ (Eq. 6).

$$
\text { Heatwave Mean Length }{ }_{y, i, j}=\text { Heatwave Days }_{y, i, j} / \text { Heatwave Count } t_{y, i, j}
$$

\subsubsection{Heatwave mean degrees over threshold}

The heatwave mean degrees metric is the mean ${ }^{\circ} \mathrm{C}$ above the threshold value for each grid cell and is calculated yearly as heatwave degree days divided by the heatwave days for grid cell $(i$, j) (Eq. 7). It provides a measure of the intensity of the heatwave.

$$
\text { Heatwave Mean Degrees }_{y, i, j}=\text { Heatwave Degrees }_{y, i, j} / \text { Heatwave Days }_{y, i, j}
$$




\subsection{Heatwave indexes change}

To observe trends that deviate from the historical mean and to make it possible to compare values across locations, we calculate the change in index compared with a baseline, defined as the mean of each index across years for the period 1986-2005. For each index and for each year from 1980 to 2018, the difference was calculated relative to the baseline. Since this calculation is the same for all heatwave indexes, we summarise the change calculation for a given year for any of the heatwave indexes as Eq. 8:

$$
\text { heatwave index change } e_{y, i, j}=\text { heatwave index } x_{y, i, j} \text {-heatwave index baseline } e_{i, j}
$$

where heatwave index $x_{y, i}$ is any given heatwave index from Table 2, heatwave index baseline $e_{i}$ $j$ is the baseline mean of that index, and heatwave index change $e_{y, i, j}$ is the change relative to the baseline for that year.

\subsection{Exposure of vulnerable population to change in heatwaves}

Exposure to heatwaves is used as an index of the human health risk factor. It provides a method of aggregated risk tracking that can be applied globally by using high-resolution population and demographic datasets. The vulnerable population was defined as people over 65. The exposure for a given year is calculated in the same way for each index, which we summarise as Eq. 9:

$$
\text { exposure to change in index } x_{y, i, j}=P_{y, i, j}^{65+} \times \text { heatwave index change } e_{y, i, j}
$$

where exposure to change in index $x_{y, i, j}$ is the yearly exposure for a given heatwave index in Table $2, P_{y, i, j}^{65+}$ is the number of people over the age of 65 , and heatwave index change $e_{y, i, j}$ is the change relative to baseline for the selected index.

\subsection{Global and exposure weighted means of heatwaves and exposures}

\subsubsection{Global mean}

The global mean values take into account all grid cells (land and sea), weighted by grid cell area.

\subsubsection{Exposure weighted mean}

Exposure weighted mean values for each index are calculated by weighting the chosen heatwave index change by the relative fraction of the relevant population in each grid cell, as shown in Eq. 10, where total population in the age band $P_{y}^{65+}=\sum_{i, j} P_{y, i, j}^{65+}$. Trends over time of the exposure weighted mean will only reflect the (change in) spatial distribution of vulnerable population and not change in the total vulnerable population, because the values are normalised by the totals for each year.

$$
\text { exposure weighted mean } n_{y}=\sum_{i, j} \frac{P_{y, i, j}^{65+}}{P_{y}^{65+}} \times \text { heatwave index change } e_{y, i, j}
$$


The global exposure weighted mean by definition considers only land grid cells. For country exposures, the grid cells for the corresponding country are selected based on a country mask and the same calculation is applied, using the total vulnerable population of that country as the divisor. As a result, per-country values are only affected by changes in spatial distribution of vulnerable population within each country. Differences in population growth and demographic changes between countries are thereby factored out (e.g., strong population growth in one country will not skew the weighted mean for other countries).

\section{Results and discussion}

\subsection{Population and demographic trends}

This work merged gridded historical population data with UN WPP demographic data to produce gridded time series. It has been noted that the world's population is aging rapidly (United Nations 2015). Figure 1 summarises the global totals by age band and highlights the very rapid increase in the population over 65 from 277 million to 702 million, making it the largest single age group in 2018.

Figure 2 shows the global distribution of the change in percentage of people over 65 between 1980 and 2018. It highlights that there has been an increase of over 10 percentage points in Japan and some regions of Europe. Sub-Saharan Africa shows a slight decrease in percentage of over-65s, due to a combination of lower life expectancy and higher population growth in the study period. As a result, the population is becoming younger on average and over-65s represent a relatively smaller percentage of the total.

\subsection{Global changes}

Two aspects of global change are considered: the comparison between the global mean and the exposure weighted mean, and the total exposure values. The exposure weighted mean factors out population growth and net change in demographic distributions (i.e., the net increase in over-65 s due to aging population), and instead reflects only the changes in spatial distribution of vulnerable population relative to the spatial distribution of heatwaves. This highlights the difference between global trends and how those trends are experienced by the population.

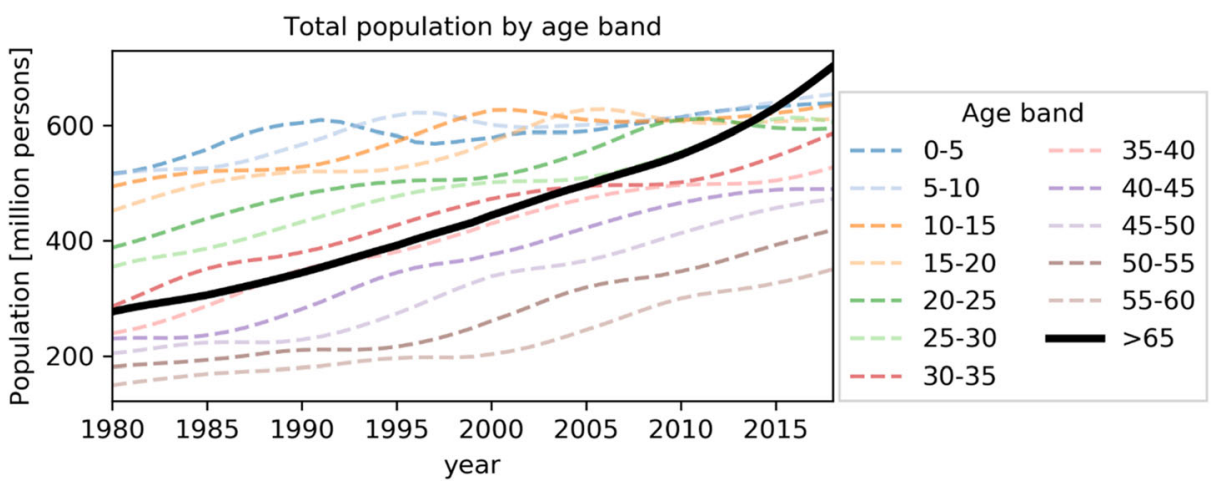

Fig. 1 Total population by age band, age band for people over 65 highlighted (solid black line) 
Change in percentage of population, $>65$

1980 to 2018

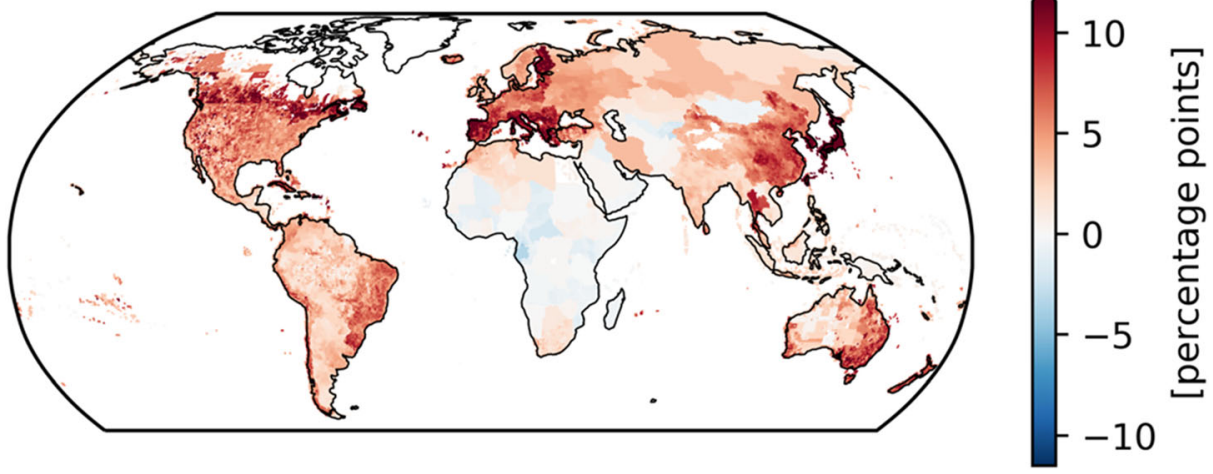

Fig. 2 Global distribution of the change in percentage points of the percentage of population over 65 between 1980 and 2018 (start and end of the period studied)

Conversely, the total exposure values capture both change in heatwave conditions and increases in both total global population and fraction of the total population over 65 . This captures the absolute change in the risk factor, which is relevant as the total need for adaptation and (medical) response measures is related to the absolute exposures rather than the mean.

The heatwave indicators are available as open access datasets ${ }^{2}$ (Chambers 2019c).

\subsubsection{Global mean changes}

Figure 3 summarises the heatwave indicator global mean and exposure weighted mean (tabulated numerical values may be found in the supplementary material). The change in heatwave degree days combines all the effects of change in heatwave occurrences, length, and intensity. We observe a dramatically stronger trend in the exposure weighted values than the global average; this indicates that heatwaves are occurring more often and with higher intensity in areas with high population. Across all grid cells in 2018, there were an average of 0.7 days of heatwave, while the vulnerable population experienced an average 3.6 days (five times higher).

The components of this trend can be better understood by inspecting the plots of the number of heatwave days per year, mean length of heatwave in days, and intensity of heatwave. The total number of days of heatwave shows a stronger trend in the exposure weighted mean than the global mean, while the mean length of heatwaves and the intensity of heatwaves appear in line with global trend, although in 2018 the global mean length was 0.2 days while the exposure weighted mean was 0.5 days. The spike in 2010 is mainly due to the June-August Russian heatwave which covered a very large area (Trenberth and Fasullo 2012).

\subsubsection{Global absolute change in exposure}

We compare global absolute change in exposure for the heatwave degree days indicator (which combines length and intensity) and the heatwave days indicator.

$\overline{{ }^{2} \text { https://zenodo.org/record/3403922 }}$ 

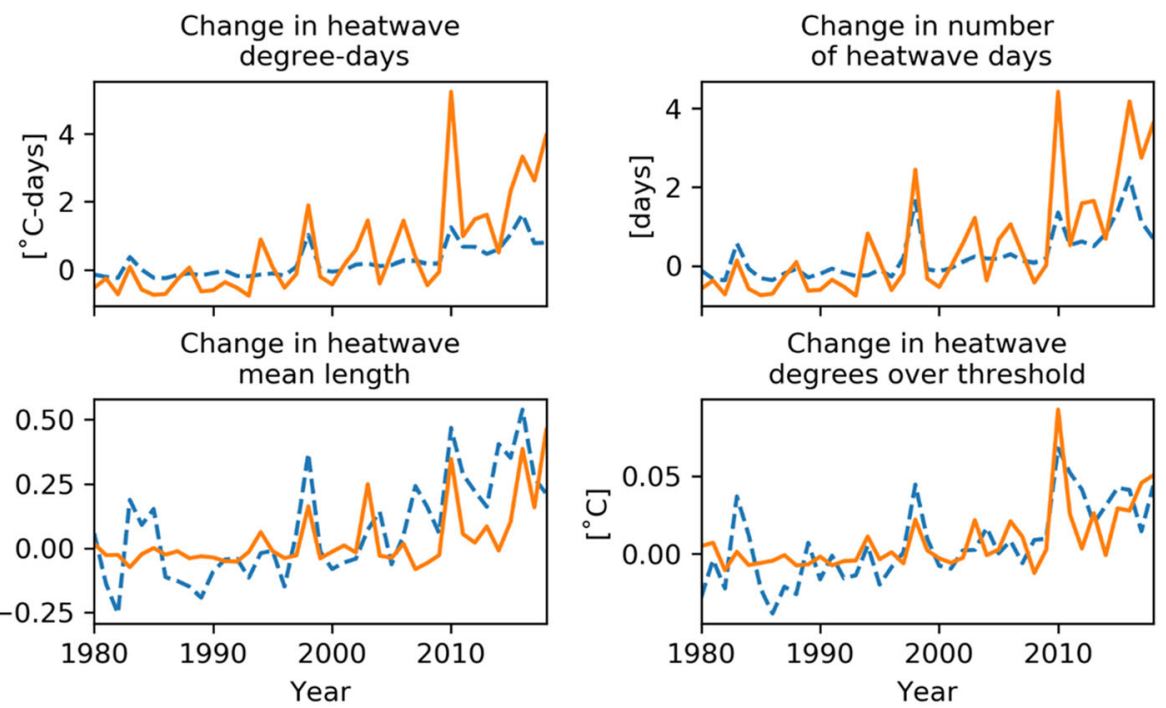

\section{--- Global mean \\ Exposure weighted mean}

Fig. 3 Global and exposure weighted means of heatwave indicators change relative to the 1986-2005 reference period

Figure 4 shows the time series of total exposures for degree days and days of heatwave, highlighting a significant increase in exposures in the past decade. Although minor differences in the year-on-year patterns exist between these two, there are no differences in the overall trend as highlighted by the 10-year moving mean line. The 10-year moving mean for 2014 (covering the period 2008-2018) gave an increase of 1.4 billion person-days exposure, while

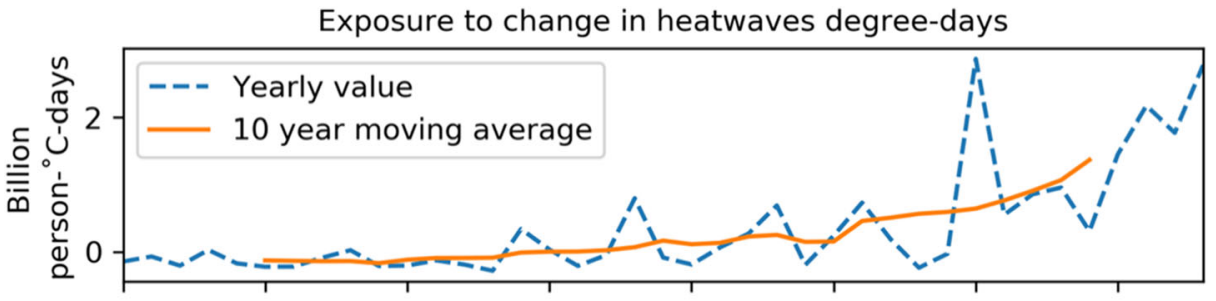

Exposure to change in heatwaves days

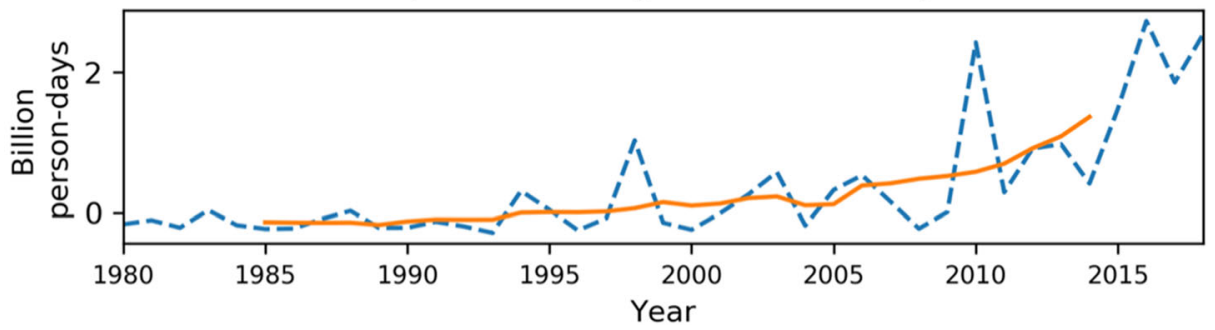

Fig. 4 Exposure to change in heatwave degree days and number of days per year relative to the mean for 19862005. The 10-year moving mean of values indicates the longer-term trend 
the maximum value recorded in 2018 was 2.5 billion person-days. There appears to be an acceleration of the trend of increase in exposure rates in the 2010-present period. This is driven by a combination of increasing heatwave days in populated areas and an increase in the total population and fraction of total population over 65-particularly in India and China. The increases in total exposures are important for health systems, as they drive the need for increased capacity to provide sufficient prevention and response services.

Given the minor differences in trends between heatwave degree days and heatwave days, we focus on the latter indicator for the remaining analysis, as we consider this metric to offer a more intuitive interpretation of the trends.

\subsection{Exposure by country}

Figure 5 shows the trend in total exposure of vulnerable people to heatwave days. The top five countries by total mean exposure over the past decade are China, India, Japan, the USA, and Indonesia; these are identified separately on the figure, highlighting in particular the large
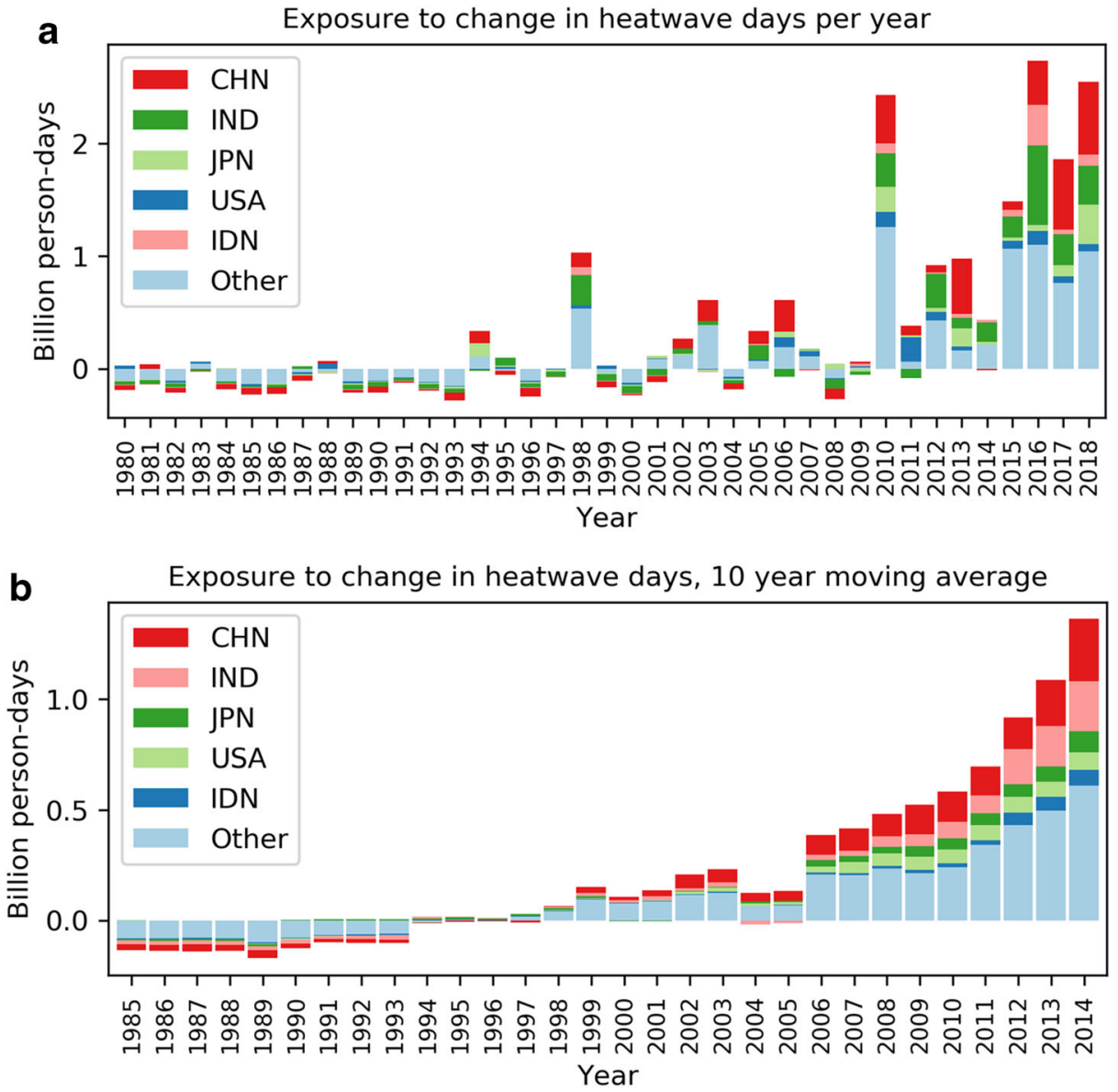

Fig. 5 Exposure to change in number of heatwave days per year relative to the reference period: a yearly, b 10year centred moving average. The top 5 countries by total exposure over the last decade are highlighted: China (CHN), India (IND), Japan (JPN), United States of America (USA), and Indonesia (IDN) 
contribution from India and China in absolute terms (227 and 281 million person-days in 2010-2018, respectively). The 10-year moving mean clearly shows the long-term trend in increasing exposure in the five countries highlighted. Tables of decadal averages may be found in the supplementary material.

The presence of Indonesia in the top five is interesting to note, as little literature was found concerning heatwaves for this country. Further research would be needed to determine whether heatwave exposures are having significant impacts in Indonesia or whether particular features of the local climate contribute to abnormally high heatwave index values.

Figure 6 summarises the decadal change weighted mean exposures per country for days of heatwave conditions per year, relative to the reference period. Figure $6 \mathrm{~d}$ covers 9 instead of 10 years as 2019 data is not yet available. These values are available in a tabular form in the supplementary material. There is a clear trend of increasing exposure to heatwave conditions over the period studied. In the 2000-2009 period, most countries displayed increased exposure, this trend being strongly reinforced in the 2010-2018 period with almost all countries experiencing a significant positive increase in exposures. In this latter period, vulnerable populations in Bhutan, Egypt, Israel, and Yemen experienced on average over a week (7 days) more heatwave than in the reference period. Particularly high increases are apparent in the Middle East and Arabian Peninsula, as well as in the Caribbean. Note that these weighted averages are not affected by total population growth within countries or differences in population growth between countries, as discussed in the "Exposure weighted mean" section. The observed changes therefore reflect the concentration of population in locations with high increases in heatwave occurrences.

\subsection{Sensitivity analysis}

A comparison was made of the different parameter choices used for the chosen definition of the heatwave. Figure 7 shows the comparison of the heatwave time series when the calculation is applied with daily mean and maximum temperature instead of minimum temperature. All indicators follow similar trends. For the global mean changes, the mean and maximum temperature-based time series are almost identical while the minimum temperatures show reduced $\min / \max$ values. Conversely, the exposure weighted values show the mean and minimum based curves being near identical while the maximum temperature based heatwave index shows reduced $\mathrm{min} / \mathrm{max}$ values.

These results suggest that relatively little change in overall trends would be expected if different temperature values were used, while evidence from health research supports the use of minimum temperatures to account for effects of lack of respite from high temperatures on health (Laaidi et al. 2012; Xu et al. 2018).

\subsection{Health system indicators}

The ability to respond to heatwave effects is related to the robustness of a country's health system. As previously noted, there is a strong relation between medical staffing levels and health outcomes; therefore, we may use the number of doctors per 10,000 inhabitants provided by the WHO as an indicator of health system capacity. Figure 8 aims at summarising the change in both heatwave effects (measured as exposure weighted mean heatwave days per country) and the medical staffing levels over the past decades. Decadal averages as calculated for Fig. 6 are plotted against mean number of doctors per 10,000 inhabitants for the corresponding decades, the most recent data point 


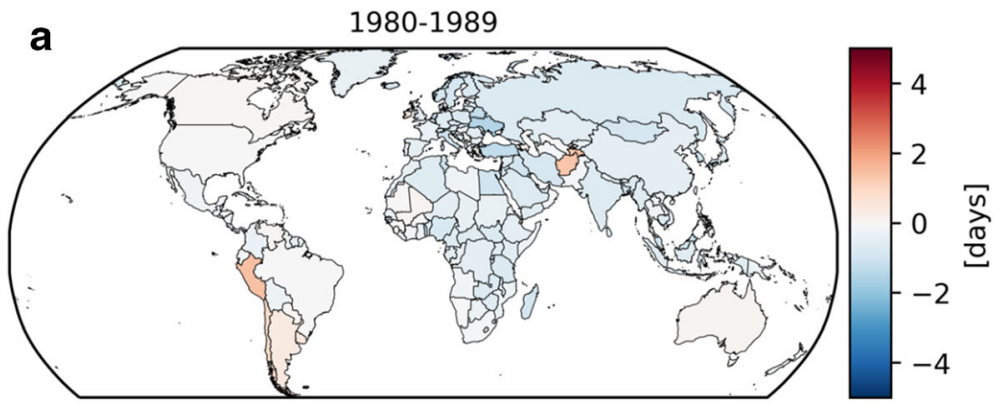

b 1990-1999
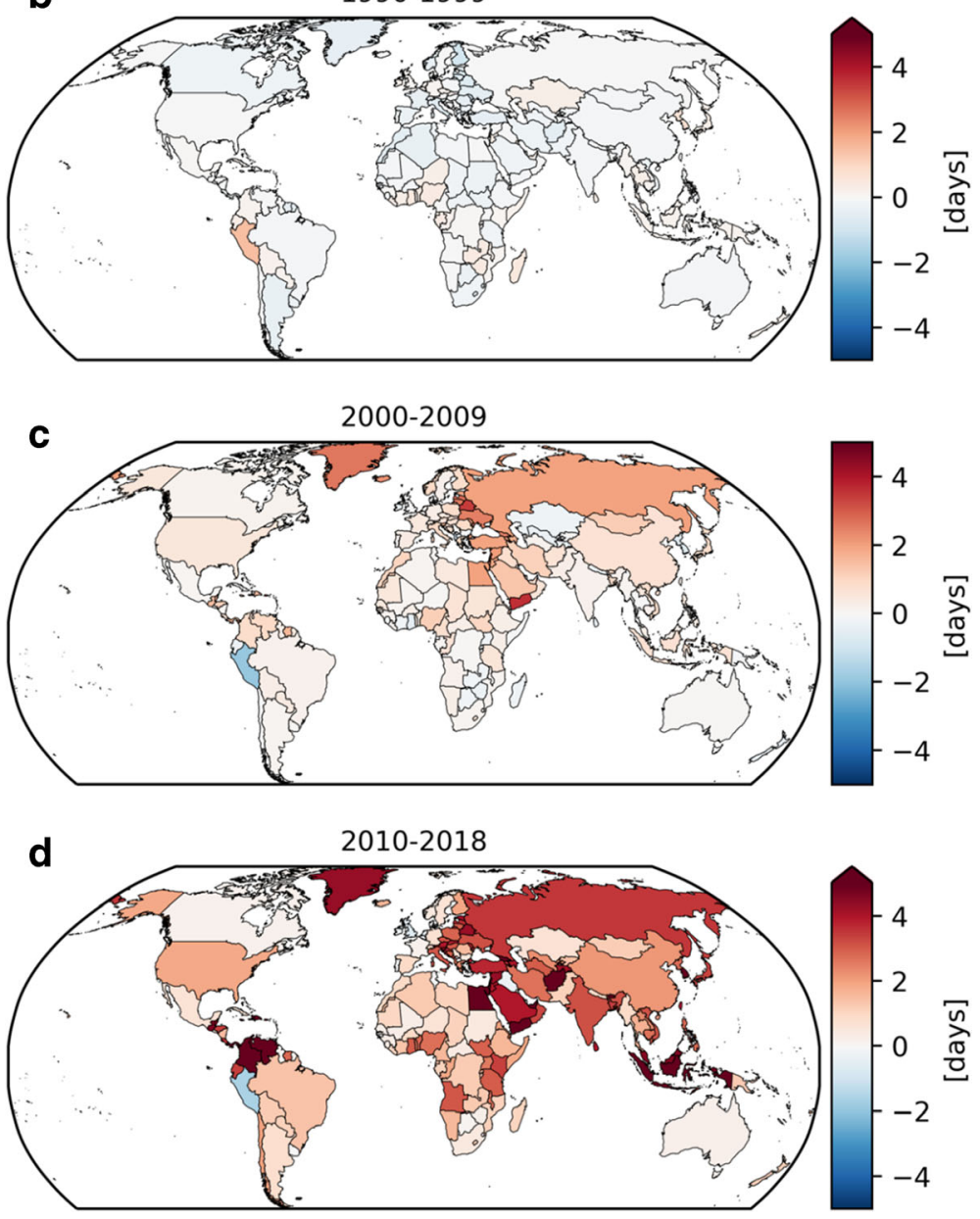

Fig. 6 Decadal averages of mean exposure of vulnerable population to changes in the number of heatwave days per year by country. Plot d covers 9 instead of 10 years. Where the colour scale ends in an arrow at the top, this indicates an open range (values may exceed that displayed on the scale)

is highlighted. As this analysis required data for both heatwaves and doctors, it was only possible to plot values for 2000-2009 and 2010-2018 due to limited data availability. 


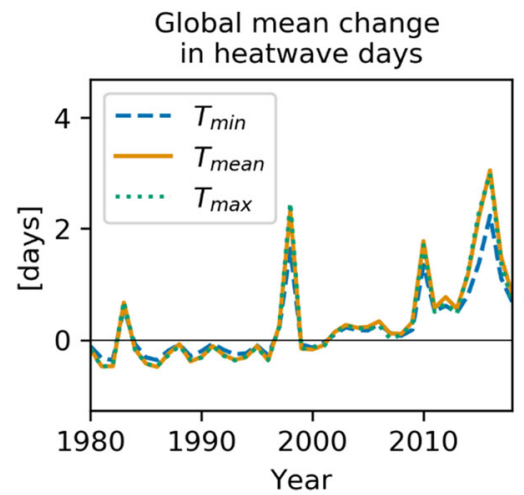

Exposure weighted change in heatwave days

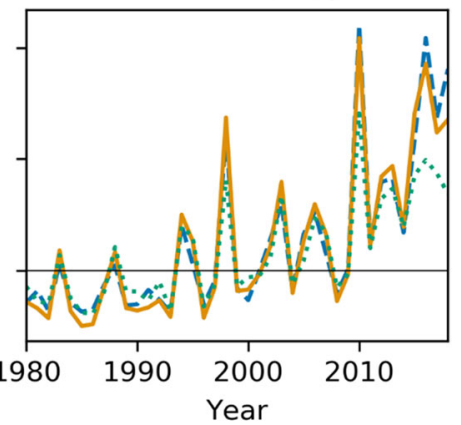

Fig. 7 Heatwave days trend calculated using the 99th percentile of daily minimum, maximum, and mean temperature

We see that while significant increases in exposure have occurred for most countries, we do not observe strong trends in medical staffing. This is particularly true of low- and low-middleincome countries (as defined by World Bank income groups). While it is not expected that heatwave occurrences should directly drive staffing levels, this does highlight a further aspect of vulnerability to heatwaves. Countries with less income are experiencing increased heatwave occurrences but do not have the high medical staff levels to help cope with the impacts, and increasing these will be challenging.

In this context, we can contrast the cases of Egypt and Cuba, being lower- and uppermiddle-income countries, respectively, but in very different situations. Cuba has a very high level of doctors per inhabitant of over 70 per 10,000, while Egypt has 8 per 10,000. Conversely, vulnerable populations in Egypt have experienced a mean increase of 12 days heatwave (exposure weighted), while in Cuba, the increase is 0.7 days. This highlights that both effects of heatwaves and response capacity with respect to heatwaves vary very significantly between countries and are affected both by changes in climate- and country-specific socioeconomic conditions. This is likely to further exacerbate global inequalities with respect

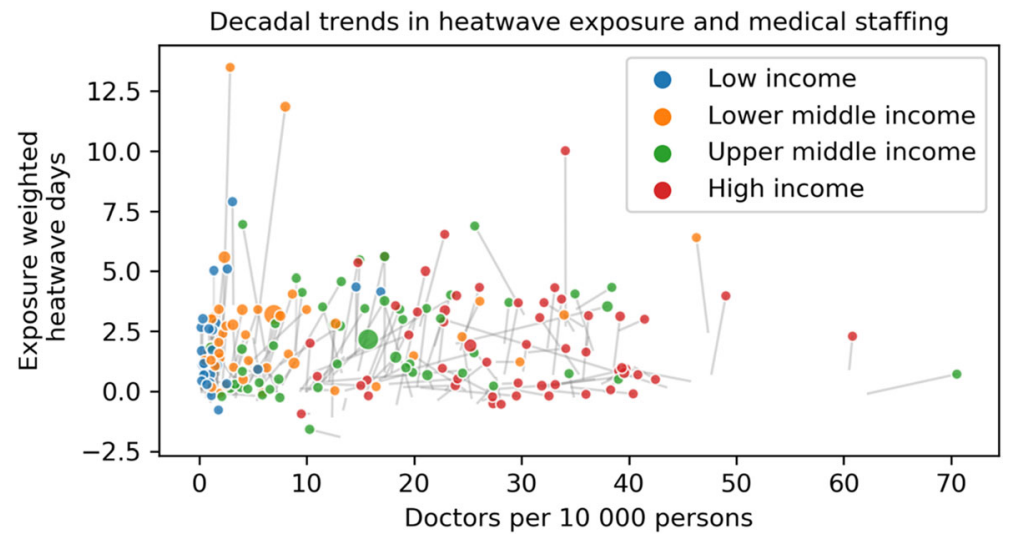

Fig. 8 Overview of decadal mean trends in heatwave exposure against medical staffing, measured as doctors per 10,000 persons. Points indicate latest data for 2010-2018, and lines indicate trends since 2000 for the corresponding point. Point sizes are proportional to country total population. Colours indicate the World Bank country income group 
to which countries experience the largest climate change impacts, in terms of direct climate effects, the vulnerability of populations to those effects, and the capacity of providing adequate health responses.

In general, we note that both low- and lower-middle-income countries have nearly uniformly low medical staffing levels, while there is a much broader range in upper-middle- and high-income countries. The former groups therefore are likely to face challenges to develop preparation and response measures. For the latter groups, it seems that country policies have a larger role in determining health coverage. Therefore, country policies could have a significant impact on heatwave preparedness by focusing efforts on preparation and response measures.

\subsection{Limitations}

A known issue with the use of ERA5 for population-focused studies is that in coastal areas, the temperatures will tend to be an average of land and sea temperatures. This will underestimate the temperatures in coastal areas, which include a large portion of the world's population. As a result, the heatwave exposures are likely to be somewhat underestimated. Future work could use the upcoming ERA5-Land dataset, which restricts the climate reanalysis to land pixels only, resulting in higher resolution data which is also more accurate over land. This study followed standard practice in calculating change values relative to the 1986-2005 reference period, thereby minimizing any potential climate reanalysis data mean bias errors. Overall, we consider the uncertainty contribution from the climate data to be low.

This study considered only ambient air temperature, while it is known that the combination of high heat and humidity also has significant health impact (Lin et al. 2009). A reliable index combining temperature and humidity is not straightforward (Kjellstrom et al. 2017; Watts et al. 2018); this should be a topic of future research. Nevertheless, as humidity is an aggravating factor for health impacts, we can consider that our results set an exposure baseline. If humidity were to be included, we would likely expect higher exposures overall.

The generation of gridded population data is complex, and the resulting data includes a level of uncertainty that is difficult to quantify. In order to maintain consistency, the "UN WPP adjusted" variant of the NASA GPWv4 data was used together with other UN WPP demographic data thereby defining the UN provided values as the authoritative baseline for the analysis. Nevertheless, there remains significant uncertainty in the population values particularly in areas with poor data collection (e.g., conflict zones). However, it was not feasible to address all of these in the context of this global study.

For demographic data, a simplifying assumption was made that the relative spatial distribution of population for each age band within each country remained approximately constant while the per-country totals per age band were adjusted to match the UN data. It is possible that demographic distributions within countries change over time due to population movements and other factors. While the total population movements over time are captured by the population data, we cannot know if such movements are caused mainly by particular subsets of age groups (e.g., young people moving to cities). Other factors include lifestyles, wealth, or health care which may evolve differently in different parts of a country resulting in changes in demographic makeup over the period studied. By calibrating to UN data, we aim for consistency at the country level. Extending this to sub-national units would be extremely challenging and likely explains why no such dataset already exists covering the time span considered. 
Finally, this study considered the dimensions of vulnerability the age group, healthcare staffing, and income group. There is a large range of potential vulnerability factors that could be considered such as gender and income inequality. Consequently, there is considerable scope for further work on these topics.

\section{Conclusion}

This study developed heatwave indexes from global climate reanalysis data and combined these with global population, demographic, and health data covering the period from 1980 to 2018. This enabled a global and cross-country analysis of heatwave exposure trends among vulnerable people. We demonstrated that there is a clear trend in increasing heatwave days globally, in accordance with climate model predictions for the effects of anthropogenic climate change. Heatwaves are being experienced by vulnerable populations at a higher rate than the global average. Furthermore, heatwave exposures in absolute terms are increasing rapidly, driven by a combination of increasing heatwave frequency, growing population, and aging of the population resulting in a larger number of people over 65 years old.

These results are significant in that they are produced from observational data of the recent past, rather than based on future projections, and therefore highlight the reality of climate change impacts that have already happened. Ongoing work aims at maintaining updates of these indicators as new data becomes available.

Heatwave index trends were combined with country health system metrics and economic metrics (World Bank income group). This highlighted the large disparities in health and wealth relative to heatwave trends. While heatwaves affect all countries irrespective of wealth, this study highlights that certain countries are at additional risk of negative impacts due to the combination of high heatwave exposure, low medical staffing, and low income. These factors exacerbate inequalities between countries with respect to climate change impacts. By tabulating these indicators per country, further work can be performed to explore other factors of vulnerability, to determine the relation between vulnerability and excess mortality, and to consider response strategies.

The increasing exposure of vulnerable people to heatwaves indicates the importance of considering climate change impacts in healthcare, in terms of both national planning and international development. We recommend that healthcare entities be fully engaged in climate mitigation and adaptation efforts to address this growing risk factor. The large increases in absolute exposures highlight the need for capacity building to match the increased needs. This paper provides a suitable statistical background which can be used to inform further policy development in national and international agencies.

Funding Open access funding provided by University of Geneva.

Open Access This article is licensed under a Creative Commons Attribution 4.0 International License, which permits use, sharing, adaptation, distribution and reproduction in any medium or format, as long as you give appropriate credit to the original author(s) and the source, provide a link to the Creative Commons licence, and indicate if changes were made. The images or other third party material in this article are included in the article's Creative Commons licence, unless indicated otherwise in a credit line to the material. If material is not included in the article's Creative Commons licence and your intended use is not permitted by statutory regulation or exceeds the permitted use, you will need to obtain permission directly from the copyright holder. To view a copy of this licence, visit http://creativecommons.org/licenses/by/4.0/. 


\section{References}

Anand S, Bärnighausen T (2007) Health workers and vaccination coverage in developing countries: an econometric analysis. Lancet 369:1277-1285. https://doi.org/10.1016/S0140-6736(07)60599-6

Anderson BG, Bell ML (2009) Weather-related mortality: how heat, cold, and heat waves affect mortality in the United States. Epidemiology 20:205-213. https://doi.org/10.1097/EDE.0b013e318190ee08

Basagaña X, Sartini C, Barrera-Gómez J, Dadvand P, Cunillera J, Ostro B, Sunyer J, Medina-Ramón M (2011) Heat waves and cause-specific mortality at all ages. Epidemiology 22:765-772. https://doi.org/10.1097 /ede.0b013e31823031c5

Basu R, Samet JM (2002) Relation between elevated ambient temperature and mortality: a review of the epidemiologic evidence. Epidemiol Rev 24:190-202. https://doi.org/10.1093/EPIREV/MXF007

Buscail C, Upegui E, Viel J-F (2012) Mapping heatwave health risk at the community level for public health action. Int J Health Geogr 11:38. https://doi.org/10.1186/1476-072X-11-38

Campbell S, Remenyi TA, White CJ, Johnston FH (2018) Heatwave and health impact research: a global review. Health Place 53:210-218. https://doi.org/10.1016/J.HEALTHPLACE.2018.08.017

Chambers J (2019a). ERA5-derived daily temperature summary 1980-2018. https://doi.org/10.5281 /ZENODO.3403963

Chambers J (2019b). Percentiles of daily mean, min, and max temperature 1986-2005. https://doi.org/10.5281 /ZENODO.3403951

Chambers J (2019c). Heatwave indexes 1980-2018. https://doi.org/10.5281/ZENODO.3403922

Gasparrini A, Guo Y, Hashizume M, Kinney PL, Petkova EP, Lavigne E, Zanobetti A, Schwartz JD, Tobias A, Leone M, Tong S, Honda Y, Kim H, Armstrong BG (2015a) Temporal variation in heat-mortality associations: a multicountry study. Environ Health Perspect 123:1200-1207. https://doi.org/10.1289/ehp.1409070

Gasparrini A, Guo Y, Hashizume M, Lavigne E, Zanobetti A, Schwartz J, Tobias A, Tong S, Rocklöv J, Forsberg B, Leone M, De Sario M, Bell ML, Armstrong B et al (2015b) Mortality risk attributable to high and low ambient temperature: a multicountry observational study. Lancet 386:369-375. https://doi. org/10.1016/S0140-6736(14)62114-0

Goldewijk KK, Beusen A, Doelman J, Stehfest E, Hague T (2017) Anthropogenic land use estimates for the Holocene - 927-953

Guo Y, Gasparrini A, Armstrong BG, Tawatsupa B, Tobias A, Lavigne E, Coelho M d SZS, Pan X, Kim H, Hashizume M, Honda Y, Guo YL et al (2016) Temperature variability and mortality: a multi-country study. Environ. Health Perspect 124:1554-1559. https://doi.org/10.1289/EHP149

Guo Y, Gasparrini A, Armstrong BG, Tawatsupa B, Tobias A, Lavigne E, Coelho M d SZS, Pan X, Kim H, Hashizume M, Honda Y, Guo Y-LL et al (2017) Heat wave and mortality: a multicountry. Multicommunity Study Environ Health Perspect 125:087006. https://doi.org/10.1289/EHP1026

Guo Y, Gasparrini A, Li S, Sera F, Vicedo-Cabrera AM, de Sousa Zanotti Stagliorio Coelho M, Saldiva PHN, Lavigne E, Tawatsupa B, Punnasiri K et al (2018) Quantifying excess deaths related to heatwaves under climate change scenarios: a multicountry time series modelling study. PLoS Med 15:e1002629. https://oi. org/10.1371/journal.pmed.1002629

Hajat S, Kosatky T (2010) Heat-related mortality: a review and exploration of heterogeneity. J Epidemiol Community Health 64:753-760. https://doi.org/10.1136/jech.2009.087999

Herold N, Alexander L, Green D, Donat M (2017) Greater increases in temperature extremes in low versus high income countries. Environ Res Lett 12. https://doi.org/10.1088/1748-9326/aa5c43

Hoyer S, Hamman J (2016) Xarray: N-D labeled arrays and datasets in Python. prep, J. Open Res. Softw

IPCC (2013a) Fifth Assessment Report - Climate Change 2013 [WWW Document]. URL http://www.ipcc. ch/report/ar5/wg1/ (accessed 5.10.16)

IPCC (2013b) Climate Change 2013: The Physical Science Basis. Contribution of Working Group I to the Fifth Assessment Report of the Intergovernmental Panel on Climate Change. Cambridge University Press, Cambridge, UK

Kenney WL, Hodgson JL (1987) Heat tolerance, thermoregulation and ageing. Sport Med 4:446-456. https://doi. org/10.2165/00007256-198704060-00004

Kilbourne EM (1997) Heat waves and hot environments. public Heal. Conseq. disasters 245-69

Kjellstrom T, Freyberg C, Lemke B, Otto M, Briggs D (2017) Estimating population heat exposure and impacts on working people in conjunction with climate change. Int J Biometeorol 62:291-306. https://doi. org/10.1007/s00484-017-1407-0

Krau SD (2013) The impact of heat on morbidity and mortality. Crit Care Nurs Clin North Am 25:243-250. https://doi.org/10.1016/j.ccell.2013.02.009

Laaidi K, Zeghnoun A, Dousset B, Bretin P, Vandentorren S, Giraudet E, Beaudeau P (2012) The impact of heat islands on mortality in Paris during the august 2003 heat wave. Environ Health Perspect 120:254-259. https://doi.org/10.1289/ehp.1103532 
Li M, Gu S, Bi P, Yang J, Liu Q (2015) Heat waves and morbidity: current knowledge and further direction-a comprehensive literature review. Int. J. Environ. Res. Public Health 12:5256-5283. https://doi.org/10.3390 /ijerph120505256

Lin S, Luo M, Walker RJ, Liu X, Hwang SA, Chinery R (2009) Extreme high temperatures and hospital admissions for respiratory and cardiovascular diseases. Epidemiology 20:738-746. https://doi.org/10.1097 /EDE.0b013e3181ad5522

Mora C, Dousset B, Caldwell IR, Powell FE, Geronimo RC, Bielecki CR, Counsell CWW, Dietrich BS, Johnston ET, Louis LV, Lucas MP et al (2017) Global risk of deadly heat. Nat Clim Chang 7:501-506. https://doi.org/10.1038/nclimate3322

Nairn J, Fawcett R (2013) Defining heatwaves: heatwave defined as a heat-impact event servicing all communiy and business sectors in Australia, CAWCR technical report 551.5250994

NASA SEDAC, CIESIN (2016). Gridded population of the world, version 4 (GPWv4): population count

Oudin Åström D, Bertil F, Joacim R (2011). Heat wave impact on morbidity and mortality in the elderly population: a review of recent studies. Maturitas. https://doi.org/10.1016/j.maturitas.2011.03.008

Perkins SE (2015) A review on the scientific understanding of heatwaves - their measurement, driving mechanisms, and changes at the global scale. Atmos Res 164-165:242-267. https://doi.org/10.1016/J. ATMOSRES.2015.05.014

Perkins SE, Alexander LV, Nairn JR (2012) Increasing frequency, intensity and duration of observed global heatwaves and warm spells. Geophys. Res. Lett. 39:2012GL053361. https://doi.org/10.1029/2012 GL053361

Perkins-Kirkpatrick SE, Gibson PB (2017) Changes in regional heatwave characteristics as a function of increasing global temperature. Sci Rep 7:12256. https://doi.org/10.1038/s41598-017-12520-2

Russo S, Sillmann J, Fischer EM (2015) Top ten European heatwaves since 1950 and their occurrence in the coming decades. Environ Res Lett 10:124003. https://doi.org/10.1088/1748-9326/10/12/124003

Sarr AB, Diba I, Basse J, Sabaly HN, Camara M (2019) Future evolution of surface temperature extremes and the potential impacts on the human health in Senegal. African J Environ Sci Technol 13:482-510. https://doi. org/10.5897/ajest2019.2757

Scalley BD, Spicer T, Jian L, Xiao J, Nairn J, Robertson A, Weeramanthri T (2015) Responding to heatwave intensity: excess heat factor is a superior predictor of health service utilisation and a trigger for heatwave plans. Aust. N. Z. J. Public Health 39:582-587. https://doi.org/10.1111/1753-6405.12421

Smith C, Levermore G (2008) Designing urban spaces and buildings to improve sustainability and quality of life in a warmer world. Energy Policy 36:4558-4562. https://doi.org/10.1016/J.ENPOL.2008.09.011

Speybroeck N, Kinfu Y, Poz MRD, Evans DB (2006). Reassessing the relationship between human resources for health, intervention coverage and health outcomes

Trenberth KE, Fasullo JT (2012) Climate extremes and climate change: the Russian heat wave and other climate extremes of 2010. J. Geophys. Res. Atmos. 117, n/a-n/a. https://doi.org/10.1029/2012JD018020

UN (2019) World Population Prospects 2019: Data Booklet

United Nations (2015) World population ageing. New York, USA, New York

Watts N, Adger WN, Agnolucci P, Blackstock J, Byass P, Cai W, Chaytor S, Colbourn T, Collins M, Cooper A, Cox PM, Depledge J, Drummond et al (2015) Health and climate change: policy responses to protect public health. Lancet 386:1861-1914. https://doi.org/10.1016/S0140-6736(15)60854-6

Watts N, Adger WN, Ayeb-Karlsson S, Bai Y, Byass P, Campbell-Lendrum D, Colbourn T, Cox P, Davies M, Depledge M, Depoux A et al (2016) The Lancet Countdown: tracking progress on health and climate change. Lancet 0:1693-1733. https://doi.org/10.1016/S0140-6736(16)32124-9

Watts N, Amann M, Ayeb-Karlsson S, Belesova K, Bouley T, Boykoff M, Byass P, Cai W, Campbell-Lendrum D, Chambers J et al (2017) The Lancet Countdown on health and climate change: from 25 years of inaction to a global transformation for public health. Lancet 391:581-630. https://doi.org/10.1016/S0140-6736(17 32464-9

Watts N, Amann M, Arnell N, Ayeb-Karlsson S, Belesova K, Berry H, Bouley T, Boykoff M, Byass P, Cai W, Campbell-Lendrum D, Chambers J, Costello A et al (2018) The 2018 report of the Lancet Countdown on health and climate change: shaping the health of nations for centuries to come. Lancet 392:2479-2514. https://doi.org/10.1016/S0140-6736(18)32594-7

Watts N, Amann M, Arnell N, Ayeb-Karlsson S, Belesova K, Boykoff M, Byass P, Cai W, Campbell-Lendrum D, Capstick S, Chambers J, et al. (2019) The 2019 report of the Lancet Countdown on health and climate change: ensuring that the health of a child born today is not defined by a changing climate. Lancet. https://doi.org/10.1016/S0140-6736(19)32596-6

WHO (2009) Global Health Risks

WHO Global Health Observatory [WWW Document] (2019) WHO. URL https://www.who.int/gho/about/en/ (accessed 9.4.19) 
WMO (2015) Guidelines on the definition and monitoring of extreme weather and climate events. Task Team Defin Extrem Weather Clim Events 62. https://doi.org/10.1016/j.corsci.2014.12.017

World Bank (2018). GDP per capita PPP - current international \$

Wright CY, Kapwata T, Wernecke B, Garland RM, Nkosi V, Shezi B, Landman WA, Mathee A (2019) Gathering the evidence and identifying opportunities for future research in climate, heat and health in South Africa: the role of the South African Medical Research Council. South African Med J 109:20-24. https://doi.org/10.7196/SAMJ.2019.v109i11b.14253

$\mathrm{Xu} \mathrm{Z}$, Cheng J, Hu W, Tong S (2018) Heatwave and health events: a systematic evaluation of different temperature indicators, heatwave intensities and durations. Sci Total Environ 630:679-689. https:/doi. org/10.1016/J.SCITOTENV.2018.02.268

Zhao Q, Coelho MSZS, Li S, Saldiva PHN, Hu K, Abramson MJ, Huxley RR, Guo Y (2018) Spatiotemporal and demographic variation in the association between temperature variability and hospitalizations in Brazil during 2000-2015: a nationwide time-series study. Environ Int 120:345-353. https://doi.org/10.1016/j. envint.2018.08.021

Zhao Q, Li S, Coelho MSZS, Saldiva PHN, Hu K, Huxley RR, Abramson MJ, Guo Y (2019) The association between heatwaves and risk of hospitalization in Brazil: a nationwide time series study between 2000 and 2015. PLoS Med 16:e1002753. https://doi.org/10.1371/journal.pmed.1002753

Publisher's note Springer Nature remains neutral with regard to jurisdictional claims in published maps and institutional affiliations. 